\title{
Commodity Prices, Tax Purpose Recognition and Bitcoin Volatility: Using ARCH/GARCH Modeling*
}

\author{
Raja Nabeel-Ud-Din JALAL ${ }^{1}$, Massimo SARGIACOMO ${ }^{2}$, Najam Us SAHAR ${ }^{3}$
}

Received: July 03, 2020 Revised: September 19, 2020 Accepted: October 05, 2020

\begin{abstract}
The study investigates the role of commodity prices and tax purpose recognition on bitcoin prices. Since the introduction of bitcoin in 2008, emphasis has focused on economists, policy-makers and analysts drastically increasing bitcoin's accessibility and commodity values (Dumitrescu \& Firică, 2014). This study employs GARCH and EGARCH from ARCH/GARCH family on daily nature data. We measure the volatile behavior of bitcoin by employing auto-regressive conditional heteroscedasticity model with the aim to explore the relationship between major commodities and bitcoin volatility. We focus on major commodities like gold, silver, platinum, and crude oil to be regressed with bitcoin. The daily prices of commodities were retrieved from www.investing.com and bitcoin prices from www.coindesk.com for the period from 29April 2013 to 16 October 2018. Results confirmed the currency's long-term volatile behavior, which is due to its composition and market dynamics, whereas the existence of asymmetric information effect is not confirmed. Tax recognition by other countries may in future help in controlling the volatility as bitcoin is not a country-specific security. But, only silver impacts on volatility in comparison to oil prices and platinum, which is due to its similar features with gold. Eventually, bitcoin can be used for risk diversification and money making.
\end{abstract}

Keywords: Bitcoin, Commodity Prices, Recognition, ARCH, GARCH

JEL Classification Code: G2, G4, B23

\section{Introduction}

Since the emergence of bitcoin in 2008, the drastic increase in bitcoin's usability and market price gain the

*Acknowledgements:

[1] All authors contributed equally in writing and conceptualization of paper idea. Categorically, Jalal has contributed in conceptual framework and data analysis. Sargiacomo contributed in writeup, reviewing and Sahar contributed in interpretation technical linkage and write-up.

[2] We declare that there is no conflict of interest regarding publication of this paper.

${ }^{1}$ First Author and Corresponding Author. PhD Researcher, Dipartmento di Economia Aziendale, Università degli Studi "G.d'A" Chieti-Pescara, Italy [Postal Address: Viale Pindaro 42, 65127 Pescara, Italy] Email: nabeel.jalal@unich.it

${ }^{2}$ Ordinary Professor of Accounting, Dipartmento di Economia Aziendale, Università degli Studi "G.d'A" Chieti-Pescara, Italy. Email: msargiacomo@unich.it

${ }^{3}$ Assistant Professor of Finance, FMS, Riphah International University, Islamabad, Pakistan.

Email: Najam.sahar@riphah.edu.pk

(C) Copyright: The Author(s)

This is an Open Access article distributed under the terms of the Creative Commons Attribution Non-Commercial License (https://creativecommons.org/licenses/by-nc/4.0/) which permits unrestricted non-commercial use, distribution, and reproduction in any medium, provided the original work is properly cited. attention of economists, policy-makers and researchers (Dumitrescu \& Firică, 2014). Financial markets are controlled by national, regional or global regulators (Malone \& Horst, 2008). This control mechanism helps to ensure stability in the economic system. But there is no concrete mechanism available regarding cryptocurrencies that ensures the safety and regulator's reach in the market. Due to high volatility observed in cryptocurrencies, researchers have tried to understand the determinants of these currencies (Bouri, Gupta, Lau, Roubaud, \& Wang, 2018; Ciaian, Rajcaniova, \& Kancs, 2016; Dyhrberg, 2016b) to define the factors that influence cryptocurrency prices. Investors use bitcoin to gain profit as in most countries it is not taxed or taxed like normal currency. ${ }^{1}$ This exclusion from the financial system lead to no governance setup, which would define the control mechanism in the market to ensure fair value in trading and transaction, and caused inflation in bitcoin value. The high volatile nature of bitcoin makes it highly risky asset in terms of investment and any information can create volatility, which can appreciate or depreciate its value (Bouri, Gupta, \& Roubaud, 2019). In a liquidity perspective, it is highly liquid, but due to high price it is difficult to convert in cash, which creates the exchange limitation. Caporale, Gil-Alana, 
and Plastun, (2018) analyzed the long-term behavior of cryptocurrencies and reported their market inefficiency.

Recent advance on bitcoin's formal recognition provides new arena of research. In 2015, United Sates "Commodity Future Trading Commission" has classified bitcoin as a "commodity". ${ }^{2}$ Later in 2016, a US federal judge ruled that bitcoin is a fund. Apart from the US, other countries have started to legalize ${ }^{3}$ bitcoin for tax purposes, which means a governance system can be implemented and volatility in bitcoin will decrease with continuous development of crypto-legal framework. Israel has implemented a strict policy on bitcoin and other cryptocurrency taxes to control the negative use of cryptocurrencies in its territory ${ }^{4}$.

Deceleration of bitcoin as a type of commodity indicates that it is also sensitive to the rest of commodities present in market as well as to other macroeconomic indicators. ${ }^{4}$ Dyhrberg (2016a) analyzes the impact of dollar and gold prices on bitcoin volatility and reports that bitcoin can be used as security for portfolio management. The uncertainty in crypto-exchange market is a new stream of literature, which solely focuses on the factors revolving around cryptocurrencies' determinants. It also tries to predict its behavior under the influence of certain dynamics determining its market value (Ciaian et al., 2016; Kristoufek, 2015). The use of the dollar as intrinsic value for bitcoin, makes it vulnerable to macroeconomic factors, and the regulatory setup is weak, which makes it a highly risky asset. However, countries have started to recognize bitcoin as asset, currency, tool of payment to control any fraudulent practices, which damage the national financial system.

Also, to get tax benefits, recognition can create positive or negative signal in the crypto-market We have followed a similar approach (Ajaz \& Kumar, 2018; Baek \& Elbeck, 2015; Bariviera, Basgall, Hasperué, \& Naiouf, 2017; Bouri, Gupta, \& Roubaud, 2019; Brière, Oosterlinck, \& Szafarz, 2015; Caporale et al., 2018; Corbet, Meegan, Larkin, Lucey, \& Yarovaya, 2018; Decker \& Wattenhofer, 2013; Dyhrberg, 2016a; Gronwald, 2014; Nakamoto, 2008; Chan, Chu, Nadarajah, \& Osterrieder, 2017; Panagiotidis, Stengos, \& Vravosinos, 2018; Phillip, Chan, \& Peiris, 2018; Selgin, 2015; Yermack, 2015). We have also explored the relation of tax-based recognition on bitcoin price volatility. The paper is organized into literature, data and methodology, and conclusion sections.

\section{Literature Review}

The word cryptocurrency is now known by everyone after the entrance of bitcoin in the market, but the general population as well as researchers and policymakers are still curious about the potential use of this technological innovation. Cryptocurrencies like Bitcoin, Ethereum, Ripple, and others, use open source codes to resolve the problem related to "peer to peer networking". This peer networking is different from the conventional money. The rules and regulations of creation are different from normal currency as it is issued as legal tender by an authorized body and used by the state and its citizens for trade. However, this phenomenon is not applicable in cryptocurrencies, as the network follows the client-server model, but connected by a set of nodes into self-organized networks. In this network the nodes can perform the dual function of client as well as server. The cost incurred in these peers-to-peer network establishment is high, through the maintenance is less than client-server network, but it is not that important.

Other than this, the cryptocurrencies like bitcoin also rely on open source software as the codes are not patented and distributed for free use. But these cryptocurrencies are now modifying their system to comply with governance mechanism as now governments are interfering to stop the negative use of bitcoin and other currencies. In case of bitcoin it was announced that, like conventional money, there is a limit on issuing. Currently, the limit is 21 millions of bitcoins that can be traded in the market (Nakamoto, 2008). And an increase occurs by inelasticity principle every four years as the increase is halved and triggers a decreasing pattern that tries to control money (Friedman, 1969).

With establishment of crypto-market finance literature, which was primarily stagnant to stock and bond markets along with industrial and firm level literature has started to evolve. The application of core finance theories and their modified versions (keeping in view crypto market) is helping in understanding the behavior of cryptocurrencies. More than a payment instrument, cryptocurrencies are used for trading and investment purposes. Due to lack of recognition cryptocurrencies are facing hurdles ( Trinh, Nguyen, Nguyen \& Ngo, 2020 ; Chu, Chan, Nadarajah, \& Osterrieder, 2017; Nadarajah \& Chu, 2017; Chan et al., 2017)which also decrease the information availability in market and creates irrationality in market. Under this circumstance, the decisions are based on market behavior and movement, not on rational. This irrationality creates a hype in investment if market observe move upward, which cause herding and lead to market crash (Ajaz \& Kumar, 2018; Jalal, Sargiacomo, Sahar, \& Fayyaz, 2020).Thus, it indicates that crypto-market are highly volatile.

With bitcoin's success, cryptocurrencies have become a new asset for investment. Due to high volatility and market capitalization growth, the dynamics of modern cryptocurrencies have begun to gain traction in literature, and researchers are studying their determinants and associations (Ciaian et al., 2016; Ciaian, Rajcaniova, \& Kancs, 2018; Jalal, Zeb \& Fayyaz, 2019; Li \& Wang, 2017; Panagiotidis et al., 2018). Cryptocurrencies are highly speculative, and irrational behavior makes them more difficult to predict than relying on basic feelings that impact more on other currencies. Scientists initially began discussing the factors and components of 
cryptocurrencies and how they contribute to the current financial system (Cheah \& Fry, 2015; Katsiampa, 2017). But researchers have been critically evaluating bitcoin and other cryptocurrencies since the last two years in terms of their efficiency, portfolio management, and risk diversification (Cheah \& Fry, 2015; Chu et al., 2017; Corbet, Lucey, Urquhart, \& Yarovaya, 2019; Fry, 2018; Fry \& Cheah, 2016; Gandal \& Halaburda, 2016; Gandal, Hamrick, Moore, \& Oberman, 2018; Jalal et al., 2020; Osterrieder \& Lorenz, 2017; Siddiqui \& Erum, 2016; Vidal-Tomás, Ibáñez, \& Farinós, 2018). There are limited studies based on interdependencies (Ciaian et al., 2016; Jalal et al., 2020)), and relationship (Chu et al., 2017; Gandal \& Halaburda, 2016; Gandal et al., 2018; Osterrieder \& Lorenz, 2017). In the crypto-market, Bouri et al. (2019) investigated the herding behavior.

\section{Data and Methodology}

According to Bariviera et al. (2017), because of long-run memory and persistence of volatility, ARCH/GARCH models are particularly suitable to study volatility. Similarly, Glaser, Zimmermann, Haferkorn, Weber, and Siering (2014) and Gronwald (2014) have incorporated the linear GARCH models. Bouoiyour and Selmi (2016) and Dyhrberg (2016b) used Threshold GARCH (T-GARCH) to study good and bad news effect. E-GARCH and CMT-GARCH are used by Bouoiyour and Selmi (2016) and Dyhrberg (2016b). In this study, we employed GRACH $(1,1)$ and EGARCH $(1,1)$ to analyze how commodity prices and tax recognition in the US and Israel impact the bitcoin price volatility. Equation (i) states the mean equation (i) and GRACH (ii) and EGARCH the equation (iii).

$$
\begin{gathered}
r_{t}=c+\sum_{i=1}^{s} \varnothing r_{t-i}+u_{t} \\
u_{t}=h_{t} z_{t}, z_{t} \sim \text { i. i.d. }(0,1)
\end{gathered}
$$

Where, " $r_{t}$ " defines the bitcoin return at time period t i.e., day, " $u_{t}$ " is the error term, " $z_{t}$ " white process and " $h_{t}$ " defines the conditional standard deviation.

$$
h_{t}^{2}=\omega+\alpha u_{t-1}^{2}+\beta h_{t-1}^{2}
$$

$$
\begin{aligned}
\log \left(h_{t}^{2}\right)=\omega & +\alpha\left[\left|\frac{u_{t-1}^{2}}{h_{t-1}}\right|-\sqrt{2 / \pi}\right] \\
& +\beta \log \left(h_{t-1}^{2}\right)+\delta \frac{u_{t-1}}{h_{t-1}}
\end{aligned}
$$

We focus on major commodities like gold, silver, platinum, and crude oil to be regressed with bitcoin. The daily prices of commodities were retrieved from www.investing. com and bitcoin prices from www.coindesk.com for the period from April 29, 2013, to October 16, 2018; descriptive statistics are reported in Table 1 . Figure 1 provides the graphical representation of movements. To understand the role of recognition of bitcoin by economies for investment, tax or payment perspective we have selected economies like the United States and Israel. The recognition dummy recorded " 1 " as recognition period and " 0 " as no recognition period in terms of taxes. Commodities and recognition were added stepwise in models to identify their effects. Cheah and Fry (2015) conducted initial studies to understand the reason of fluctuation using volatility modeling.

\section{Results and Discussion}

With respect to mode $1,2,3,4$ the mean equation indicates that AR (1) is significant meaning today's returns are predicted by past returns, which are less as the coefficient sign is negative. In model 1 , the variance equation indicates that economic shocks exist in bitcoin prices; the big shock creates big volatility and vice-versa. Also, GARCH effect is significant, which indicates the persistence of volatility in bitcoin, and the cumulative of both effects is near 1 meaning persistence is in the long run. This is due to the fact that the cryptocurrency market is new and there is no concrete regulatory setup indicating high volatility. Moreover, the results in model 1 and $2 \operatorname{GARCH}(1,1)$ indicate that recognition from the US and Israel of bitcoin for taxation purpose has significant impact on volatility. However, the magnitude of the effect is small, which means that legal recognition by US and Israel authorities have not caused any drastic fluctuation in bitcoin volatility. It may be due to the fact that bitcoin is not governed by a single country as it is a global security.

Table 1: Descriptive Statistics

\begin{tabular}{|l|c|c|c|c|}
\hline & Bitcoin Return & Platinum & Oil & Silver \\
\hline Mean & 0.001928 & -0.026032 & -0.092156 & -0.024877 \\
\hline Maximum & 0.248357 & 0.037863 & 0.116213 & 0.120505 \\
\hline Minimum & -0.345410 & -0.329927 & -0.329927 & -0.163774 \\
\hline Std. Dev. & 0.044436 & 0.060531 & 0.149047 & 0.059748 \\
\hline No. Obs. & 1989 & 1989 & 1989 & 1989 \\
\hline
\end{tabular}



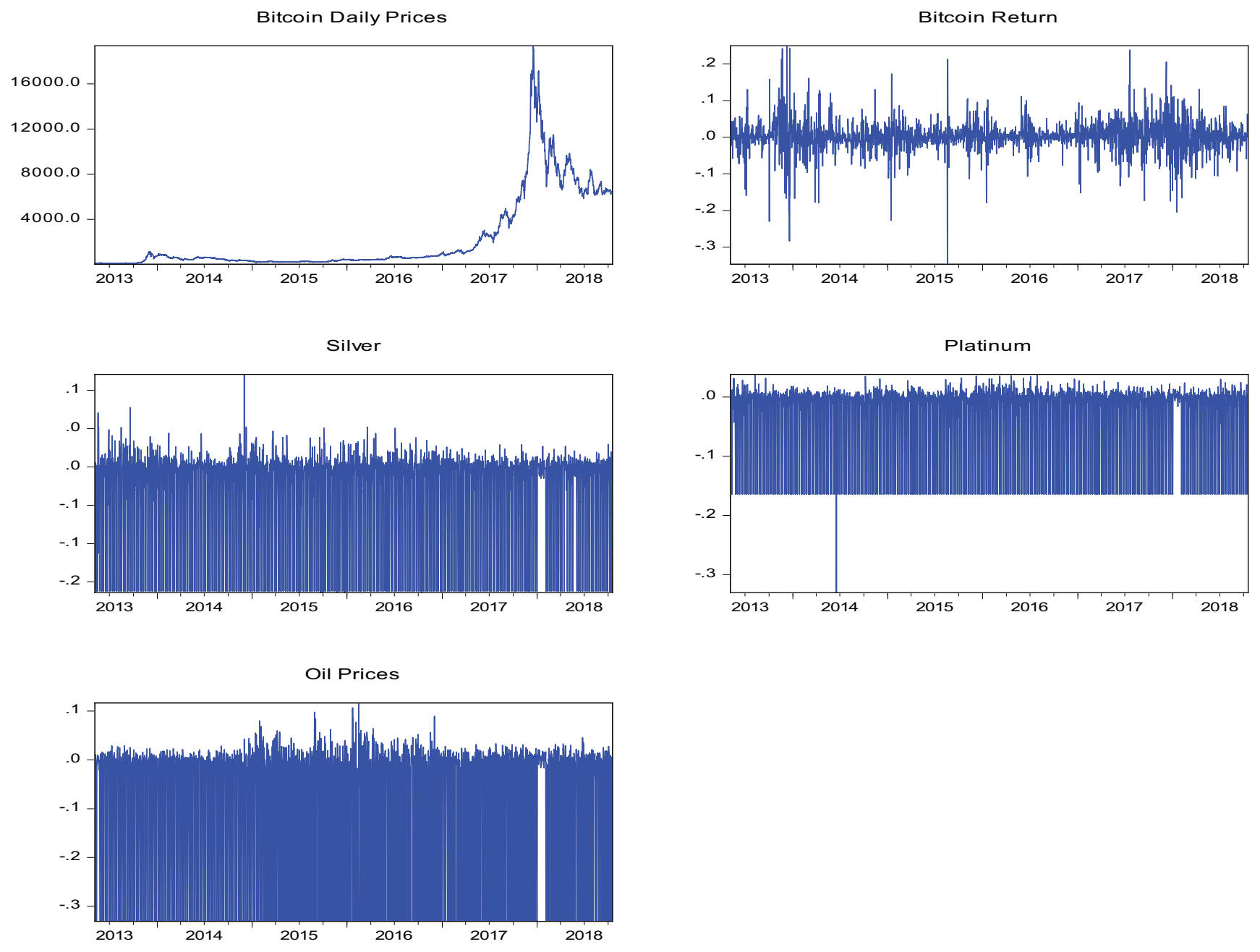

Figure 1: Prices and Returns of Bitcoin, Silver, Platinum and oil Prices returns

Further, platinum has no effect on bitcoin volatility; it may be because platinum unlike gold or silver it not much use in the jewelry industry. Gold (Dyhrberg, 2016a; Hammoudeh \& Yuan, 2008; Yermack, 2015) and silver resale value is determined by market, but platinum resale value depreciates. Whereas, the silver market price influences the bitcoin price volatility because of its tradability and use as a wealth-generation asset like gold. As Jalal and Sahar (2020) reported that oil price has a significant relation with equities as it is a volatile market and highly linked with firms and economic growth. Considering this, it was supposed that oil futures will have the same pattern as bitcoin. However, oil future price does not influence the bitcoin price volatility, though it is a highly volatile asset like bitcoin. Oil prices are determined by market forces and production, and the oil market has a regulatory setup that is absent in bitcoin's case as it is considered as unregulated market or market with least regulatory holdup and prices are inflated. Interestingly, in both model (1\&2) GARCH term is highly significant and dominates the ARCH term, which means that cryptocurrencies like bitcoin are highly volatile and this volatile behavior is of long-run phenomenon.

Further, to understand the impact of asymmetry bitcoin price volatility, EGARCH is employed for this purpose, which is one of the asymmetric GARCH models to capture asymmetric news effect on volatility. The results in model 3 and 4 indicate that the size effect is significant and means that big shock creates big volatility and vice versa. Also, GARCH effect is significant indicating persistence of volatility in bitcoin, and the cumulative effect is more than one (1), which means persistence is in the long run. In both models, persistence dominates the shocks because of the dynamics, trading mechanism, and governance mechanism associated with bitcoin (Hammoudeh \& Yuan, 2008). 
Raja Nabeel-Ud-Din JALAL, Massimo SARGIACOMO, Najam Us SAHAR /

Table 2: GARCH and EGARCH Estimation

\begin{tabular}{|c|c|c|c|c|}
\hline Predictors & Model $1_{a}$ & Model $2_{a}$ & Model 3 & Model $4_{b}$ \\
\hline Const.(c) & $\begin{array}{l}.0012^{* *} \\
(.0004)\end{array}$ & $\begin{array}{l}.0016^{\star *} \\
(.0004)\end{array}$ & $\begin{array}{l}.0016^{\star *} \\
(.0004)\end{array}$ & $\begin{array}{l}.0016^{* *} \\
(.0004)\end{array}$ \\
\hline $\operatorname{AR}(1)\left(\varphi_{1}\right)$ & $\begin{array}{l}-.058^{* *} \\
(.017)\end{array}$ & $\begin{array}{l}-.055^{* *} \\
(.017)\end{array}$ & $\begin{array}{l}-.055^{* *} \\
(.017)\end{array}$ & $\begin{array}{l}-.055^{* *} \\
(.017)\end{array}$ \\
\hline Const. $(\omega)$ & $\begin{array}{l}4.83 E-05^{* *} \\
(2.13 E-05)\end{array}$ & $\begin{array}{l}7.37 \mathrm{E}-05^{* *} \\
(2.66 \mathrm{E}-05)\end{array}$ & $\begin{array}{l}-.426^{* *} \\
(.077)\end{array}$ & $\begin{array}{l}-.047^{* *} \\
(.090)\end{array}$ \\
\hline$A R C H(\alpha)$ & $\begin{array}{l}.179^{* *} \\
(.029)\end{array}$ & $\begin{array}{l}.177^{*} \\
(.029)\end{array}$ & $\begin{array}{l}.304^{* *} \\
(.035)\end{array}$ & $\begin{array}{l}.308^{* *} \\
(.037)\end{array}$ \\
\hline GARCH $(\beta)$ & $\begin{array}{l}.827^{* *} \\
(.021)\end{array}$ & $\begin{array}{l}.817^{* *} \\
(.023)\end{array}$ & $\begin{array}{l}.961^{* *} \\
(.009)\end{array}$ & $\begin{array}{l}.950 * \\
(.010)\end{array}$ \\
\hline$E G A R C H(\delta)$ & & & $\begin{array}{l}.023 \\
(.021)\end{array}$ & $\begin{array}{l}.018 \\
(.022)\end{array}$ \\
\hline Platinum & $\begin{array}{c}6.07 E-05 \\
(.00049)\end{array}$ & $\begin{array}{l}-.0001 \\
(.0005)\end{array}$ & $\begin{array}{c}.489 \\
(1.13)\end{array}$ & $\begin{array}{c}.363 \\
(1.18)\end{array}$ \\
\hline Silver & $\begin{array}{c}.0013^{* *} \\
(.00052) \\
\end{array}$ & $\begin{array}{l}.0012^{* *} \\
(.0005) \\
\end{array}$ & $\begin{array}{l}2.375^{* *} \\
(1.117) \\
\end{array}$ & $\begin{array}{l}2.412^{* *} \\
(1.667) \\
\end{array}$ \\
\hline Oil prices & $\begin{array}{c}-.00025 \\
(.0002)\end{array}$ & $\begin{array}{l}-.00028 \\
(00027)\end{array}$ & $\begin{array}{l}-.348 \\
(.340)\end{array}$ & $\begin{array}{l}-.383 \\
(.354)\end{array}$ \\
\hline US & & $\begin{array}{l}-3.75 E-05^{* *} \\
(1.91 E-05)\end{array}$ & & $\begin{array}{l}-.044^{* *} \\
(.0184)\end{array}$ \\
\hline Israel & & $\begin{array}{c}7.56 \mathrm{E}-05^{* *} \\
(3.45-05)\end{array}$ & & $\begin{array}{l}.045^{* *} \\
(.020)\end{array}$ \\
\hline
\end{tabular}

Interestingly, EGARCH, which analyzes the asymmetric behavior is insignificant, but the direction is positive meaning that good news will create more volatility than bad news. It can be concluded that negative and positive shocks have no asymmetric effect on bitcoin and it can be used for hedging purpose as it can hedge risk (Dyhrberg, 2016b). In contrast, in our case, asymmetric information has no impact on volatility. Similarly, like model 1 and 2, platinum and oil prices have shown no association with bitcoin volatility with reference to model 3 and 4 . The reasons are similar to those stated above: usage and regulatory setup (see Jalal and Sahar ,2017). Consequently, recognition by US and Israel authorities of bitcoin for taxation with the motive to control illegal practices has significant impact on bitcoin volatility, which indicates that strong regulations in future may affect bitcoin. However, the effect captured by EGARCH equation indicates that US and Israel tax recognition effect is small, which means that this will cause no drastic fluctuation in bitcoin volatility ${ }^{3}$. Besides, bitcoin market will move as per its regular pattern, until a vast majority of financially-strong economies updates their legal framework and implement crypto-governance mechanism in their respective territories.

\section{Conclusion}

Cryptocurrencies are a new phenomenon and people are still experiencing its unique pattern of movement day by day. Investors are using bitcoin as asset (apart from the main feature of exchange) and use it for profit earning by hedging, diversification and income hiding (Bouri et al., 2018; Bouri, Gupta, \& Roubaud, 2019; Bouri, Molnár, Azzi, Roubaud, \& Hagfors, 2017; Devenow \& Welch, 1996; Dyhrberg, 2016b, 2016b; Jalal et al., 2020; Platanakis \& Urquhart, 2019; Vidal-Tomás et al., 2018). We tried to investigate the role of commodity prices and tax purpose recognition on volatility of bitcoin. Our results confirmed that recognition has a certain level of influence on volatility. The tax recognition by other countries may in future help controlling the volatility as bitcoin is not a country-specific security. Only silver impacts on volatility in comparison to oil prices and platinum, which is due to its similar features like gold. Eventually, bitcoin can be used for risk diversification and money making. 


\section{References}

Ajaz, T., \& Kumar, A. S. (2018). Herding in Crypto-Currency Markets. Annals of Financial Economics, 13(02), 1850006. https://doi.org/10.1142/s2010495218500069

Baek, C., \& Elbeck, M. (2015). Bitcoins as an investment or speculative vehicle? A first look. Applied Economics Letters, 22(1), 30-34. https://doi.org/10.1080/13504851.2014.916379

Bariviera, A. F., Basgall, M. J., Hasperué, W., \& Naiouf, M. (2017). Some stylized facts of the Bitcoin market. Physica A: Statistical Mechanics and Its Applications, 484, 82-90. https:// doi.org/10.1016/j.physa.2017.04.159

Bouoiyour, J., \& Selmi, R. (2016). Bitcoin: A beginning of a new phase? Economics Bulletin, 36(3), 1430-1440.

Bouri, E., Gupta, R., Lau, C. K. M., Roubaud, D., \& Wang, S. (2018). Bitcoin and global financial stress: A copula-based approach to dependence and causality in the quantiles. Quarterly Review of Economics and Finance, 69, 297-307. https://doi.org/10.1016/j. qref.2018.04.003

Bouri, E., Gupta, R., \& Roubaud, D. (2019). Herding behaviour in cryptocurrencies. Finance Research Letters, 29, 216-221. https://doi.org/10.1016/j.frl.2018.07.008

Bouri, E., Molnár, P., Azzi, G., Roubaud, D., \& Hagfors, L. I. (2017). On the hedge and safe haven properties of Bitcoin: Is it really more than a diversifier? Finance Research Letters, 20 , 192-198. https://doi.org/10.1016/j.frl.2016.09.025

Brière, M., Oosterlinck, K., \& Szafarz, A. (2015). Virtual currency, tangible return: Portfolio diversification with bitcoin. Journal of Asset Management, 16(6), 365-373. https://doi.org/10.1057/ jam.2015.5

Caporale, G. M., Gil-Alana, L., \& Plastun, A. (2018). Persistence in the cryptocurrency market. Research in International Business and Finance, 46(January), 141-148. https://doi.org/10.1016/j. ribaf.2018.01.002

Cheah, E. T., \& Fry, J. (2015). Speculative bubbles in Bitcoin markets? An empirical investigation into the fundamental value of Bitcoin. Economics Letters, 130, 32-36. https://doi. org/10.1016/j.econlet.2015.02.029

Chu, J., Chan, S., Nadarajah, S., \& Osterrieder, J. (2017). GARCH Modeling of Cryptocurrencies. Journal of Risk and Financial Management, 10(4), 17. https://doi.org/10.3390/jrfm10040017

Ciaian, P., Rajcaniova, M., \& Kancs, A. (2016). The economics of BitCoin price formation. Applied Economics, 48(19), 17991815. https://doi.org/10.1080/00036846.2015.1109038

Ciaian, P., Rajcaniova, M., \& Kancs, A. (2018). Virtual relationships: Short- and long-run evidence from BitCoin and altcoin markets. Journal of International Financial Markets, Institutions and Money, 52, 173-195. https://doi.org/10.1016/j. intfin.2017.11.001

Corbet, S., Lucey, B. M., Urquhart, A., \& Yarovaya, L. (2019). Cryptocurrencies as a Financial Asset: A Systematic Analysis.
International Review of Financial Analysis, 62. https://doi. org/10.2139/ssrn.3143122

Corbet, S., Meegan, A., Larkin, C., Lucey, B., \& Yarovaya, L. (2018). Exploring the dynamic relationships between cryptocurrencies and other financial assets. Economics Letters, 165, 28-34. https://doi.org/10.1016/j.econlet.2018.01.004

Decker, C., \& Wattenhofer, R. (2013). Information propagation in the Bitcoin network. In: 13th IEEE International Conference on Peer-to-Peer Computing, IEEE P2P 2013 - Proceedings. https://doi.org/10.1109/P2P.2013.6688704

Devenow, A., \& Welch, I. (1996). Rational Herding in Financial Economics. European Economic Review, 40(3-5), 603-615. https://doi.org//doi.org/10.1016/0014-2921(95)00073-9

Dumitrescu, D., \& Firică, O. (2014). A turbulent IT currency infant in the global business environment. International Conference of the Institute for Business Administration - The Digital Economy: Challenge or Growth Driver for SMEs and Corporations?, 79-94. Retrieved April 20, 2020 from https:// www.srac.ro/calitatea/arhiva_suplimente.html\#2014

Dyhrberg, A. H. (2016a). Bitcoin, gold and the dollar - A GARCH volatility analysis. Finance Research Letters, 16, 85-92. https:// doi.org/10.1016/j.frl.2015.10.008

Dyhrberg, A. H. (2016b). Hedging capabilities of bitcoin. Is it the virtual gold? Finance Research Letters, 16, 139-144. https:// doi.org/10.1016/j.frl.2015.10.025

Friedman, M. (1969). The Optimum Quantity of Money. Piscataway, NJ: Transaction Publishers

Fry, J. (2018). Booms, busts and heavy-tails: The story of Bitcoin and cryptocurrency markets? Economics Letters, 171, 225-229. https://doi.org/10.1016/j.econlet.2018.08.008

Fry, J., \& Cheah, E. T. (2016). Negative bubbles and shocks in cryptocurrency markets. International Review of Financial Analysis, 47, 343-352. https://doi.org/10.1016/j. irfa.2016.02.008

Gandal, N., \& Halaburda, H. (2016). Can We Predict the Winner in a Market with Network Effects? Competition in Cryptocurrency Market. Games, 7(3), 16. https://doi.org/10.3390/g7030016

Gandal, N., Hamrick, J. T., Moore, T., \& Oberman, T. (2018). Price manipulation in the Bitcoin ecosystem. Journal of Monetary Economics, 95, 86-96. https://doi.org/10.1016/j. jmoneco.2017.12.004

Glaser, F., Zimmermann, K., Haferkorn, M., Weber, M. C., \& Siering, M. (2014). Bitcoin - Asset or Currency? Revealing Users' Hidden Intentions. In: Proceedings of the Twenty Second European Conference on Information Systems. Tel Aviv, Israel. 9-11 June 2014. http://aisel.aisnet.org/ecis2014/

Gronwald, M. (2014). The Economics of Bitcoins - Market Characteristics and Price Jumps. In: CESifo Working Paper No. 5121. Retrieved April 20, 2020 from: http://hdl.handle. net/10419/107282\%0AStandard-Nutzungsbedingungen: 
Hammoudeh, S., \& Yuan, Y. (2008). Metal volatility in presence of oil and interest rate shocks. Energy Economics, 30(2), 606-620. https://doi.org/10.1016/j.eneco.2007.09.004

Jalal, R. N.-U.-D., \& Sahar, N. U. (2020). Asian Emerging Market Perspective of Macroeconomic Factors, Stock Return, and Volatility. International Journal of Management, 11(08), 14561475. https://doi.org/10.34218/IJM.11.8.2020.133

Jalal, R. N. U. D., Zeb, N., \& Fayyaz, U. E. R. (2019). The effect of personality traits on employee job satisfaction with moderating role of islamic work ethics. Journal of Asian Finance, Economics and Business, 6(2), 161-171. https://doi. org/10.13106/jafeb.2019.vol6.no2.161

Jalal, R. N.-U.-D., Sargiacomo, M., Sahar, N. U., \& Fayyaz, U. (2020). Herding Behavior and Cryptocurrency: Market Asymmetries. Journal of Asian Finance, Economics and Business, 7(7), 27-34. https://doi.org/10.13106/jafeb.2020. vol7.no7.027

Katsiampa, P. (2017). Volatility estimation for Bitcoin: A comparison of GARCH models. Economics Letters, 158, 3-6. https://doi.org/10.1016/j.econlet.2017.06.023

Kristoufek, L. (2015). What are the main drivers of the bitcoin price? Evidence from wavelet coherence analysis. PLOS ONE, 10(4), 1-15. https://doi.org/10.1371/journal.pone.0123923

Li, X., \& Wang, C. A. (2017). The technology and economic determinants of cryptocurrency exchange rates: The case of Bitcoin. Decision Support Systems, 95, 49-60. https://doi. org/10.1016/j.dss.2016.12.001

Malone, S. W., \& Horst, E. T. (2008). The Black Market for Dollars in Venezuela. Emerging Markets Finance \& Trade, 46(5), 67-89.

Nadarajah, S., \& Chu, J. (2017). On the inefficiency of Bitcoin. Economics Letters, 150, 6-9. https://doi.org/10.1016/j.econlet. 2016.10.033

Nakamoto, S. (2008). Bitcoin: A Peer-to-Peer Electronic Cash System. White Paper. Retrieved April 20, 2020 from: https:// bitcoin.org/bitcoin.pdf

Chan, S., Chu, J., Nadarajah, S., \& Osterrieder, J. (2017). A Statistical Analysis of Cryptocurrencies. Journal of Risk and Financial Management, 10(2), 12. https://doi.org/10.3390/ jrfm10020012

Osterrieder, J., \& Lorenz, J. (2017). a Statistical Risk Assessment of Bitcoin and Its Extreme Tail Behavior. Annals of Financial Economics, 12(1), 1750003. https://doi.org/10.1142/ s2010495217500038

Panagiotidis, T., Stengos, T., \& Vravosinos, O. (2018). On the determinants of bitcoin returns: A LASSO approach. Finance
Research Letters, 27, 235-240. https://doi.org/10.1016/j. frl.2018.03.016

Phillip, A., Chan, J., \& Peiris, S. (2018). A new look at Cryptocurrencies. Economics Letters, 163, 6-9. https://doi. org/10.1016/j.econlet.2017.11.020

Platanakis, E., \& Urquhart, A. (2019). Should investors include Bitcoin in their portfolios? A portfolio theory approach. British Accounting Review, 52(4), 100837. https://doi.org/10.1016/j. bar.2019.100837

Selgin, G. (2015). Synthetic commodity money. Journal of Financial Stability, 17, 92-99. https://doi.org/10.1016/j. jfs.2014.07.002

Siddiqui, M. A., \& Erum, N. (2016). Modeling Effect of Exchange Rate Volatility on Growth of Trade Volume in Pakistan. Journal of Asian Finance, Economics and Business, 3(2), 33-39. https:// doi.org/10.13106/jafeb.2016.vol3.no2.33.

Vidal-Tomás, D., Ibáñez, A. M., \& Farinós, J. E. (2018). Herding in the cryptocurrency market: CSSD and CSAD approaches. Finance Research Letters, 30, 181-186. https://doi. org/10.1016/j.frl.2018.09.008

Yermack, D. (2015). Is Bitcoin A Real Currency? An Economic Appraisal. In: Handbook of Digital Currency: Bitcoin, Innovation, Financial Instruments, and Big Data (pp. 31-43). Cambridge, MA: Academic Press. https://doi.org/10.1016/ B978-0-12-802117-0.00002-3

\section{Endnotes}

'“On March 25th, 2014 United States Internal Revenue Services (IRS) issued a notice (Press release N. IR-2014-36) explained the that with effect of this notice virtual currencies will be treated as property in US territory for Federal Tax purposes. https://www.irs.gov/newsroom/irs-virtual-currency-guidance"

${ }^{2}$ "In September 17, 2015 United States "Commodity Future Trading Commission (CFTC)" released a press release(No. 7231-15) in which it recognized Bitcoin and other cryptocurrencies as commodity in US territory. https://www.cftc.gov/PressRoom/ PressReleases/pr7231-15"

3"Assessing the Differences in Bitcoin \& Other Cryptocurrency Legality Across National Jurisdiction. https://papers.ssrn.com/ sol3/papers.cfm?abstract_id=3042248"

${ }^{4}$ https://www.ccn.com/israels-tax-body-aggressively-pursuingcryptocurrency-tax-evaders/

5"https://www.forbes.com/sites/francescoppola/2018/01/01/theillogical-value-proposition-of-bitcoin/\#5c0680736218” 